\title{
Insights into Pathophysiology of Carotid Baroreceptor Stimulation as a Method for Treatment of Resistant Hypertension
}

\section{Dragan Lovića* and Branko Lovića}

Inter Medica Clinic for Internal Diseases, Niš, Serbia

*Corresponding author: Dragan Lovića, Inter Medica, Clinic for Internal Diseases, Hypertension Centre, Jovana Ristića 20-2, 18000 Niš, Mediana, Serbia, Tel: 381184244632; E-mail: draganl1@sbb.rs

Rec date: Jan 15, 2014; Acc Date: Feb 20, 2014; Pub Date: Feb 22, 2014

Copyright: (C) 2014 Lovića D, et al. This is an open-access article distributed under the terms of the Creative Commons Attribution License, which permits unrestricted use, distribution, and reproduction in any medium, provided the original author and source are credited.

\begin{abstract}
Resistant hypertension is the term used for patients who are tolerant to a maximum of three doses of antihypertensive drugs, where one of them is a diuretic. Resistant hypertension also applies to patients who are unable to reach the target blood pressure. Patients with resistant hypertension are at a higher risk of cardiovascular morbidity and mortality than those whose hypertension is controlled well.

Evidence suggests that baroreceptors play an important role in a long-term blood pressure regulation. Previous studies in animals and humans have demonstrated safe and effective blood pressure decrease with chronic electrical stimulation of the carotid sinus. Electrical baroreflex stimulation appears safe and effective and may be a useful adjunct to medical treatment in patients with resistant hypertension. This review discusses the evolution and patophysiological basis of carotid baroreceptor stimulation as well as the current data available from ongoing trials.
\end{abstract}

\section{Keywords Resistant hypertension; Baroreceptors; Carotid baroreceptor stimulation}

\section{Introduction}

Arterial hypertension (AH) is a major health problem worldwide, with a high prevalence in general population. It is also an important risk factor for cardiovascular (CVD) and renal (RD) diseases. According to WHO data, about $30-50 \%$ of the adult population suffer from $\mathrm{AH}$. The prevalence of $\mathrm{AH}$ in 2025 is expected to rise by $60 \%$ (29.2\%-1.56 billion people) from the current $26.4 \%$ (972 million people in year 2000) $[1,2]$.

Hypertension remains a major risk factor for early renal failure, stroke, heart failure and heart attack. The risk of end-stage chronic kidney disease and myocardial infarction is four times higher in persons with systolic blood pressure above $160 \mathrm{mmHg}$ than in those with normal blood pressure, and the risk of developing heart failure is two times higher in persons after the age of forty $[3,4]$.

\section{Etiopathogenesis of $\mathrm{AH}$}

Etiology of these undiagnosed diseases remains to be a major problem in the fight against AH. Today it is well known that many factors play a role in the development of hypertension and therefore we can say that the development of this disease is caused by multiple factors. The ones that may play a role in the genesis of essential hypertension can be divided into genetic (predisposition), exogenousbehavioral (obesity, excessive salt intake, physical inactivity, chronic stress, increased alcohol consumption, inadequate nutrition) and endogenous physiological factors (renin-reactivity, cell membrane dysfunction, endothelial dysfunction, prostaglandins function disorder, baroreceptor activity, etc.). There is no direct evidence that $\mathrm{AH}$ is a hereditary disease. Previous studies have indicated that a large number of genes are associated with hypertension, but it is believed that there is a risk of development of this disease in these people but that exogenous factors nevertheless play a major role in driving the neurohumoral system (endogenous factors) changes, which remain a leading process in $\mathrm{AH}$ development [2].

Epidemiological studies worldwide indicate that, in spite of the use of powerful antihypertensive drugs, less than $30 \%$ of all $\mathrm{AH}$ patients fail to keep their blood pressure below the target levels $<140 / 90 \mathrm{mmHg}$ [4]. In some hypertensive patients, it can be difficult to keep BP under control, despite the use of combinations of antihypertensive drugs. These people are considered resistant to antihypertensive treatment. Resistant hypertension is the term used for patients who are tolerant to a maximum of three doses of antihypertensive drugs, where one of them is a diuretic. Resistant hypertension also covers patients who are unable to reach target blood pressure $(<140 / 90 \mathrm{mmHg}$ for the general population and $<130 / 80 \mathrm{mmHg}$ for patients with certain comorbidities, such as diabetes mellitus, coronary heart disease and chronic kidney disease) [5-7]. Resistant hypertension includes patients whose pressure is controlled by the use of more than three medications, and patients whose pressure is controlled by four or more drugs to achieve the target BP values [8].

While the exact prevalence of resistant hypertension is unknown, clinical studies suggest that it is not rare, probably diagnosed in $20-30 \%$ of all AH patients. Considering the fact that senior citizens and obese people are at the highest risk for uncontrolled hypertension, the incidence of resistant hypertension increases as the population becomes older and more obese [8]. Estimated prevalence of resistant hypertension in ALLHAT, VALUE, CONVINCE and ASCOTT studies ranged from $7 \%$ to $15 \%[9,10]$. Patients with resistant hypertension are at a higher risk of cardiovascular morbidity and mortality than those whose hypertension is controlled well $[8,9,11]$. The increased cardiovascular risk among patients with resistant hypertension depends on blood pressure [3] and the presence of 
associated co-morbidities, including diabetes mellitus, sleep apnea, obesity, left ventricular hypertrophy and renal disease [8,12-15].

Although the role of above factors in pathogenesis of essential hypertension is well established, their involvement in mechanisms responsible for treatment resistance has not been investigated thoroughly [16].

In the emergence of drug-resistant hypertension Tsioufis et al. highlight the impact of increased activity of the sympathetic nervous system (SNS), which is particularly emphasized by co-morbidities such as hyper obesity (BMI $30 \mathrm{~kg} / \mathrm{m}^{2}$ ), sleep apnea and aldosterone excess. The authors report that listed co-morbidities inducing insulin resistance, endothelial dysfunction and inflammation lead to increased sympathetic activity that causes increased activity of the RAAS and thus the emergence of drug-resistant hypertension $[17,18]$.

More specifically, increased SNS activity has been documented in systolic-diastolic and isolated systolic AH $[19,20]$, in white coat and masked $\mathrm{AH}$ [21], in dipping, extreme dipping, non-dipping and reverse dipping condition [22] and in pregnancy induced AH [19,23].

Given the above, the treatment of patients with resistant hypertension in the last decade has attracted growing attention. However, despite the use of the strongest antihypertensive drugs, blood pressure remains out of control in 5\%-15\% of patients. Therefore, the need for alternative treatment approach has been widely recognized in recent years. That is why an interventional treatment of hypertension, which was abandoned by the end of the twentieth century, was recently re-invented and gained intense scientific interest. In this respect, in the treatment of resistant hypertension, a special attention is paid to carotid baroreceptors stimulation and to sympathetic renal denervation, which show promising preliminary results $[8,24]$.

\section{Cardiac Baroreceptors - Neurogenic Factor}

The adequate blood pressure control reduces cardiovascular risk independent of the drugclass $[25,26]$. Any therapy that can reduce blood pressure in patients with resistant hypertension may be useful. Doctors have long recognized the importance of the carotid sinus in the modulation of autonomic tone and regulation of blood pressure [26].

Carotid sinus baroreceptors are located in the bifurcation of the common carotid artery and they are mechanoreceptors that respond to vascular distension [27].

Baroreceptors (pressoreceptors) in conjunction with the vasomotor center in the medulla oblongata and vagal nuclei are involved in maintaining the normal blood pressure.

In response to a sensed "stretch", the baroreceptor sends a signal that travels from the carotid sinus nerve to join cranial nerve IX (CN IX), eventually signaling to the nucleus tractussolitariusin the medulla. Ultimately, this leads to an inhibition of sympathetic output, along with decrease in the release of renin and antidiuretic hormone, which serve to reduce the intravascular volume and tone (Figure 1) [2,27-29].

Baroreceptors inhibit sympathetic output, reducing the release of renin and anti-diuretic hormone, which reduce the intravascular volume and tone [27]. The stimulation of carotid baroreceptors reduces kidney sympathetic tone and thus expresses their effects $[30,31]$. However, on the basis of his experimental work, Lohmeier has suggested that the levels of natriuretic a trial peptide (AMP) are increased under chronic baroreflex activation, which causes enlarged excretion through the kidneys, which in turn reduces the blood pressure [32].

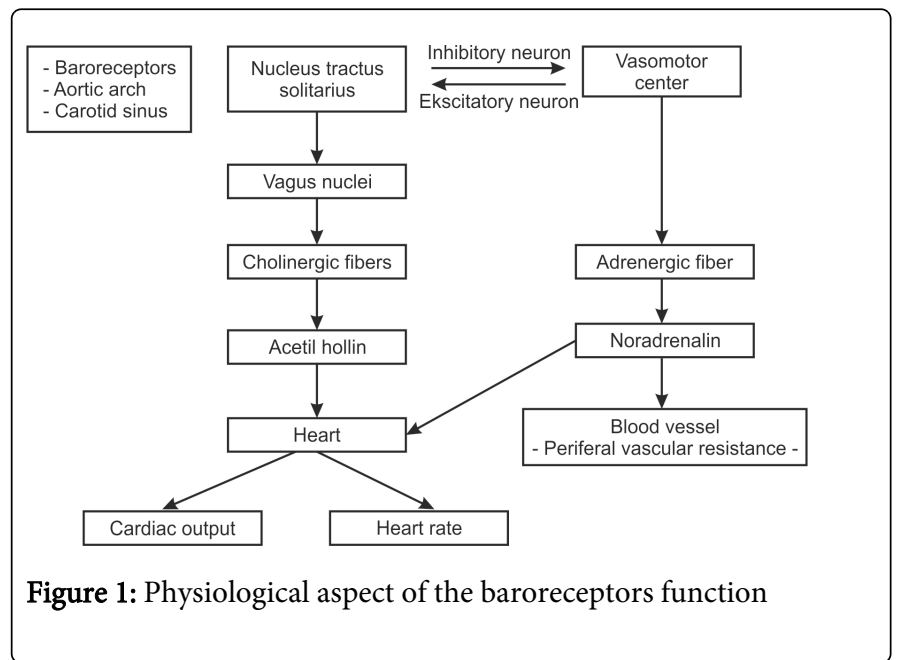

It is thought that disruption of proper functioning of this system is one of the most important factors in essential hypertension. It is assumed that a reduced sensitivity of the mentioned system to normal stimulation, or operatona at a higher sensitivity level, may lead to the increase and maintenance of high blood pressure [1].

Some animal experiments support this hypothesis by showing that when continuously stimulated in arterial hypertension, baroreceptors may fail to lower the blood pressure, which becomes physiological blood pressure but at a higher level [30]. However, some recent studies suggest that the dysfunction of baroreceptors plays a small role in the etiology of hypertension, but can influence the severity of the disease instead $[1,2]$.

\section{History of baroreceptor investigation}

Early studies of the baroreceptor's role in blood pressure modulation date back in 1950's. A study by Mc. Cubbin in 1956 investigating the baroreceptor of both normotensive and hypertensive dogs provided early evidence of the firing threshold and showed that a higher pressure was required to elicit baroreceptor function in the hypertensive dogs [33].

Studies in later decades with electrically stimulated canine carotid sinus reported an arterial blood pressure variation that was frequencydependent and maintained even over a $90 \mathrm{~min}$ period of continuous stimulation [34]. In a study published in 1958 Carlsten et al. examined humans undergoing neck/head surgery and confirmed that carotid stimulation did reduce blood pressure in a frequency-dependent manner [35].

In 1980 Peters et al. reported on experience with a device that matched a stimulator frequency to the patient heart rate, the idea being that heart rate elevations signaled increases in sympathetic tone that need to be controlled by greater activation of the baroreflex to achieve blood pressure control [36,37]. Patients implanted with this device achieved blood pressure lowering both at rest and during exercise. Effective blood pressure lowering was subsequently reported 12 years after the device implantation [36].

In the past decade, more sophisticated research has developed with the understanding that non-pharmacologic means of controlling blood 
pressure may be a realistic and necessary alternative. In 2004 Lohmeier examined normotensive dogs that underwent sustained electrical stimulation of their carotid sinuses over a 7-day period. They found an immediate fall in the mean arterial pressure (MAP) of $25 \mathrm{mmHg}$, and over the full 7 days the dogs sustained a decrease in MAP [38].

In 2005, Schmidli et al. reported results obtained on five patients who underwent chronic electrical activation of the baroreflex with a carotid stimulator [39]. The device produced a graded voltage dependent drop in blood pressure - a relationship that was sustained even with chronic activation of the baroreflex. Moreover, these patients were concurrently receiving maximum medical therapy including alpha and beta antagonist, suggesting that baroreflx activation provides incremental attenuation of sympathetic tone in the setting of oral anti-adreneric therapy. This theory is supported by experiments conducted by Irwin et al. on anesthetized dogs [40].

Schimidlli found that electrical carotid stimulation and esmolol infusion applied individually produced similar reduction in blood pressure and heart rate, but produced synergistic effect when applied simultaneously [41].

\section{Recent baroreceptor stimulation therapy}

The newest carotid sinus stimulator is a device called Rheos. It is manufactured by CVRx, Inc. (MN, USA) and consists of an implanted pulse generator with leads that tunnel subcutaneously and bilaterally attach to the carotid sinuses. The device requires surgical implantation under general anesthesia and is fully programmable after implantation to allow adjustment of the stimulation parameters [42].

Studies in humans have confirmed the efficacy of this interventional approach, which was observed in animals. Acute blood pressure reduction was noted by using the Rheos device during elective carotid surgery [31]. Several case reports in patient with resistant hypertension have shown the clinical utility and long-lasting reductions in blood pressure with carotid baroreceptor stimulation, setting the basis for proof-of-concept, properly designed clinical trials [43-45]. The devicebased therapy of hypertension (DEBuT-HT) trail in 45 patients with resistant hypertension revealed a significant reduction in both systolic and diastolic blood pressures, which was evident from the beginning of the study and was maintained thereafter [46]. The 3-year efficacy was recently presented verifying the long-lasting effect of carotid baropacing. Recruitment for a large randomized study has been completed and results are still pending. Preliminary information suggests that some patients may not respond as well and a more careful selection process may need to be implemented.

Data from an early US trail, the Rheos feasibility trail, have shown some promising results. The trial followed up 10 patients taking a median of six blood pressure medications and follow-up at 3 months, showing sustained mean systolic pressure reductions of $22 \mathrm{mmHg}$ $(\mathrm{p}=0,01)$ and mean diastolic pressure reductions of $18 \mathrm{mmHg}(\mathrm{p}<0,01)$ with no reports of orthostasis or adverse renal events [47].

The Baroreflex Activating System Study (BRASS) was conducted in 2003 at the Department of Cardiovascular Surgery at the University Hospital in Bern, Switzerland [48]. Eleven patients undergoing carotid endarterectomy were enrolled in the study. Under either local or general anesthesia, the carotid sinus was electrically stimulated, allowing acute activation of the carotid baroreflex over a range of clinically relevant intensities. This study demonstrated a reduction in systolic arterial pressure that was directly related to the intensity of stimulation of the carotid sinus. Thus, in this acute setting, activation of the carotid baroreflex produced dose dependent, controllable reduction in arterial pressure.

Stimulation of carotid barorecteptors is associated with heart rate variability and heart rate turbulence changes that are consistent with a decrease of sympathetic activity and an increase of the vagal tone. These changes are correlated with a significant blood pressure decrease. Thus, the data suggest that the modulation of the autonomic nervous system contributes to a better blood pressure control through stimulation of carotid baroreceptors in severely hypertensive patients [49].

\section{Conclusions}

Resistant hypertension affects a significant number of patients and carries a high risk of cardiovascular events. As such, any novel therapy for blood pressure control deserves our attention. Therapeutic lifestyle modification and intensive drug therapy for these patients have simply proven inadequate, leaving many patients at a drastically elevated risk from the cardiovascular complications associated with uncontrolled hypertension.

The carotid baroreflex represents an essential component of blood pressure regulation. The activation of the carotid baroreflex results in the attenuation of the sympathetic tone and subsequent blood pressure reduction. Carotid nerve activation has been used in the past for the treatment of severe hypertension, but it has been abandoned due to adverse events and several technical disadvantages. Recent technological advances have permitted the development of a new device that electrically stimulates carotid baroreceptors.

Since the current results are promising, further studies are needed to clarify the place of carotid baroreceptor stimulation in the management of patients with resistant hypertension.

\section{References}

1. Kearney PM, Whelton M, Reynolds K, Muntner P, Whelton PK, et al (2005) Global burden of hypertension: analysis of worldwide data. Lancet 365: 217-223.

2. Lovic D, Lovic B, Lovic M (2009) Etiopathogenesis of arterial hypertension. Internist 1: 13-21.

3. Lewington S, Clarke R, Qizilbash N, Peto R, Collins R; Prospective Studies Collaboration (2002) Age-specific relevance of usual blood pressure to vascular mortality: a meta-analysis of individual data for one million adults in 61 prospective studies. Lancet 360: 1903-1913.

4. Erdine S (2011) How well is hypertension controlled in Europe. ESH scientific newsletter.

5. National Institutes of Health (2003) The Seventh Report of the Joint National Committee and Prevention, Detection, Evaluation and Treatment of High Blood Pressure (JNC 7), Hypertension 42: 1206-1252.

6. Mancia G, Fagard R, Narkiewicz K, Redón J, Zanchetti A, et al. (2007) Guidelines for the management of arterial hypertension: The task force for the management of arterial hypertension of the European Society of Hypertension (ESH) and the European Society of Cardiology (ESC). J Hypertens 25: 1105-1187.

7. Sarafidis PA, Bakris GL (2008) Resistant hypertension: an overview of evaluation and treatment. J Am Coll Cardiol 52: 1749-1757.

8. Calhoun DA, Jones D, Textor S, Goff DC, Murphy TP, et al. (2008) Resistant Hypertension: Diagnosis, Evaluation and Treatment: A Scientific Statement From American Heart Association Professional Education Committee of the Council for High Blood Pressure Research. Hypertension 51: 1403-1419. 
9. Chapman N, Dobson J, Wilson S, Dahlö B, Sever PS, et al. (2007) Effect of spironolactone on blood pressure in subjects with resistant hypertension. Hypertension 49: 839-845.

10. ErdineS, Arslan E, Coca A (2011) Resistant hypertension.ESH Scientific newsletter update on Hypertension management.

11. Lovic B ,Tasic I, DeljaninIlic M, Ilic S, Djordjevic D, et al. (1998) The impact of persistent of left ventricular hypertrophy in hypertensive patients on cardiovascular events: eight year follow-up . Reprinted form, XIII World Congress of Cardiology, Monduzzieditore, International Proceedings Division, Rio de Janairo, Brazil.

12. Chobabanian AV, Bakris GL, Black HR, Cushman WC, Green LA, et al. (2003) The Seventh Report of the Joint National Committee and Prevention, Detection, Evaluation and Treatment of High Blood Pressure. JAMA 289: 2560-2572.

13. Cuspidi C, Macca G, Sampieri L, Michev I, Salerno M, et al. (2001) High prevalence of cardiac and extracardiac target organ damage in refractory hypertension. J Hypertens 19: 2063-2070.

14. Lovic D, Lovic M, Stojanov V (2010) Importance of left ventricular hypertrophy in arterial hypertension. Internist 2: 137-139

15. Jakovljevic B, Stojanov V, Lovic D, Paunovic K, Lovic M (2011) The effect of alcohol consumption on cardiovascular morbidity and mortality in a thirty-year follow up study. Internist 3: 191-196.

16. Oparil S, Zaman MA, Calhoun DA (2003) Pathogenesis of hypertension. Ann Intern Med 139: 761-776.

17. Tsioufis C, Kordalis A, Flessas D, Anastasopoulos I, Tsiachris D, et al. (2011) Pathophysiology of resistant hypertension: the role of sympathetic nervous system. Int J Hypertens 2011: 642416.

18. Jakovljevic B, Stojanov V, LoviÄ D, PaunoviÄ K, RadosavljeviÄ V, et al. (2011) Obesity and fat distribution as predictors of aortoiliac peripheral arterial disease in middle-aged men. Eur J Intern Med 22: 84-88.

19. Grassi G (2009) Assessment of sympathetic cardiovascular drive in human hypertension: achievements and perspectives. Hypertension 54: 690-697.

20. Tasic I, Lovic B, Nikolic A, Ilic S, Djordjevic D, et al. (1999) Heart rate and blood pressure variability in hypertensive patients. Facta Universitatis 6:63-69.

21. Grassi G, Seravalle G, Trevano FQ, Dell'oro R, Bolla G, et al. (2007) Neurogenic abnormalities in masked hypertension. Hypertension 50: 537-542.

22. Grassi G, Seravalle G, Quarti-Trevano F, Dell'Oro R, Bombelli M, et al. (2008) Adrenergic, metabolic, and reflex abnormalities in reverse and extreme dipper hypertensives. Hypertension 52: 925-931.

23. Schobel HP, Fischer T, Heuszer K, Geiger H, Schmieder RE (1996) Preeclampsia -- a state of sympathetic overactivity. N Engl J Med 335: 1480-1485.

24. Papademetriou V, Doumas M, Faselis C, Tsioufis C, Douma S, et al. (2011) Carotid baroreceptor stimulation for the treatment of resistant hypertension. Int J Hypertens 2011: 964394.

25. Staessen JA, Wang JG, Thijs L (2003) Cardiovascular prevention and blood pressure reduction: a quantitative overview updated until 1 March 2003. J Hypertens 21: 1055-1076.

26. Lampen H, Kerdi P, Koppermann E (1949) Experimental disinhibitoryhypertension. Z Kreislanfforschung 38: 577-592.

27. Chapleau MW (2008) Arterial baroreflexes. Hypertension primer: the essentials of high blood pressure (4thedn) Lippincott Williams \& Wilkins, London.

28. Neistadt A, Schwartz SI (1967) Effects of electrical stimulation of the carotid sinus nerve in reversal of experimentally induced hypertension. Surgery 61: 923-931.

29. Joshi N, Taylor J, Bisognano JD (2009) Implantable device therapy for the treatment of resistant hypertension. J Cardiovasc Transl Res 2: 150-153.

30. Bristow JD, Honour AJ, Pickering GW, Sleight P, Smyth HS (1969) Diminished baroreflex sensitivity in high blood pressure. Circulation 39: 48-54.
31. Christy IJ, Denton KM, Anderson WP (1994) Renal denervation potentiates the natriuretic and diuretic effects of atrial natriuretic peptide in anaesthetized rabbits. Clin Exp Pharmacol Physiol 21: 41-48.

32. Esler M, Rumantir M, Wiesner G, Kaye D, Hastings J, et al. (2001) Sympathetic nervous system and insulin resistance: from obesity to diabetes. Am J Hypertens 14: 304S-309S.

33. McCubbin JW, Green JH, Page IH (1956) Baroceptor function in chronic renal hypertension. Circ Res 4: 205-210.

34. WARNER HR (1958) The frequency-dependent nature of blood pressure regulation by the carotid sinus studied with an electric analog. Circ Res 6: 35-40.

35. Carlsten A, Folkow B, Grimby G, Hamberger CA, Thulesius O (1958) Cardiovascular effects of direct stimulation of the carotid sinus nerve in man. Acta Physiol Scand 44: 138-145.

36. Peters TK, Koralewski HE, Zerbst E (1989) Search for optimal frequencies and amplitudes of therapeutic electrical carotid sinus nerve stimulation by application of the evolution strategy. Artif Organs 13: 133-143.

37. Wallin BG, Sundlöf G, Delius W (1975) The effect of carotid sinus nerve stimulation on muscle and skin nerve sympathetic activity in man. Pflugers Arch 358: 101-110.

38. Lohmeier TE, Irwin ED, Rossing MA, Serdar DJ, Kieval RS (2004) Prolonged activation of the baroreflex produces sustained hypotension. Hypertension 43: 306-311.

39. SchmidiJ, Mohaupt M, Savolainen H (2005) Response to acute electrical activation of the carotid baroreflex is maintained in drug refractory hypertension. J Hypertens 25.

40. Irwin ED, Rossing MA, Hagen JJ (2006) Electrical activation of the carotid baroreflex enhances the sympathoinhibition in canines. J Clin Hypertens.

41. Filippone JD, Bisognano JD (2007) Baroreflex stimulation in the treatment of hypertension. Curr Opin Nephrol Hypertens 16: 403-408.

42. Schmidli J, Savolainen H, Eckstein F, Irwin E, Peters TK, et al. (2007) Acute device-based blood pressure reduction: electrical activation of the carotid baroreflex in patients undergoing elective carotid surgery. Vascular 15: 63-69.

43. Sloand JA, Illig KA, Bisognano JD (2007) Improved control of resistant hypertension with device-mediated electrical carotid sinus baroreflex stimulation. J Clin Hypertens (Greenwich) 9: 716-719.

44. Mohaupt MG, Schmidli J, Luft FC (2007) Management of uncontrollable hypertension with a carotid sinus stimulation device. Hypertension 50: 825-828.

45. Sica DA, Lohmeier TE (2006) Baroreflex activation for the treatment of hypertension: principles and practice. Expert Rev Med Devices 3: 595-601.

46. Scheffers I, Schmidli J, Kroon AA (2008) Sustained blood pressure reduction by baroreflex hypertension therapy with chronically implanted system: 2-year data from the Rheos DEBUT-HR study in patients with resistant hypertension. J Hypertens 26.

47. BisognanoJ, Sloand J, Papademetriou V, Rothstein M, Sica D, et al. (2006) An implantable carotid sinus baroreflex activating system for drug resistant hypertension: interim chronic efficacy result from the multicenter Rheos Feasibility Trail. Circulation 114: 575.

48. Schmidli J, Savolainen H, Irwin E (2004) Electrical activation of the baroreflex in man: a step towards a novel treatment for hypertension? Vascular 12: S95.

49. Wustmann K, Kucera JP, Scheffers I, Mohaupt M, Kroon AA, et al. (2009) Effects of chronic baroreceptor stimulation on the autonomic cardiovascular regulation in patients with drug-resistant arterial hypertension. Hypertension 54: 530-536. 